\title{
Condition Monitoring of the Uncoated Carbide Cutting Tool in Turning Process of the Aluminum Alloy 6061 via Vibration
}

\author{
Othman Inayatullah $^{1}$, Vickneswaran Sinnasamy ${ }^{2}$ \\ ${ }^{1}$ Departement of Mechanical and Manufacturing Engineering,School of Engineering and Technology, University College of \\ Technology Sarawak \\ ${ }^{2}$ Departement of Mechanical and Manufacturing Engineering, Faculty of Engineering, Universiti Putra Malaysia (9 pt)
}

\begin{tabular}{l}
\hline Article Info \\
\hline Article history: \\
Received May $29^{\text {th }}, 2017$ \\
Revised Aug $20^{\text {th }}, 2017$ \\
Accepted Oct $18^{\text {th }}, 2017$ \\
\hline Keyword: \\
Cutting tool \\
Turning \\
Vibration \\
Aluminum Alloy 6061 \\
Tool life \\
\hline
\end{tabular}

\begin{abstract}
This study have been conducted in an attempt to monitor the changing of tool wear caused by increasing the cutting speed, depth of cut and feed rate. The signal processing analysis was done on the raw signal, the vibration signal then which is analyses by using MATLAB software. The relationship among several parameter of vibration signal, such as energy and maximum amplitude with cutting speed and depth of cut was studied. The material machined was Aluminum Alloy 6061 and uncoated carbide as a cutting tool. At the same time, the cutting temperature was also monitored. The results show that vibration signal can be one of the method to monitor tool wear in turning process via in-situ and therefore can be obtained useful for establishing the end of tool life in these operation. Based on the results the suitable speed and depth of cut range was identified to maximize the tool life
\end{abstract}

\section{Corresponding Author:}

First Author,

Departement of Mechanical and Manufacturing Engineering,

School of Engineering and Technology,

University College of Technology Sarawak,

868 Persiaran Brooke 96000, Sibu, Sarawak, Malaysia.

Email: drothman@ucts.edu.my

\section{Introduction}

Turning is a form of machining; a material removal process which is used to create rotational parts by cutting away unwanted material. Lathes are designed for turning operations, so the precise control of the cutting results in tight tolerances. However, the desired dimensions and its precision are highly influenced by a critical phenomenon which is the cutting tool wear property. Due to the worm cutting tool, it causes vibration in the cutting tool affects due lifespan of the cutting tool and functional behaviour. There are three parameters influence the cutting tool lifespan, the cutting speed, depth of cut and tool feed rate. On other parts, the cutting speed also depends on the length, type of material and diameter of the object and problem occurs when we encounter unknown material.

The objectives of this study is to evaluate the mechanical behaviour of the cutting tool during turning by analysing the vibration signal and the relationship percentage of tool wear with vibration signal. The vibration signal propagates by the cutting tool during the cutting of the turning aluminium alloy. The amplitude and energy produced by the system increased as the vibration increase. In the thermographic testing, an images shown the worm cutting tool create more heat compared to the good one.

The cutting tool selection in turning process is among the most essential factors in machining process. The cutting tools must possess certain characteristics as they subject to high temperature, high contact stresses and rubbing along the machined surface. The important mechanical property with respect to the workpiece to be machined is the cutting tool's hot hardness as shown in Figure 1 [1]. 


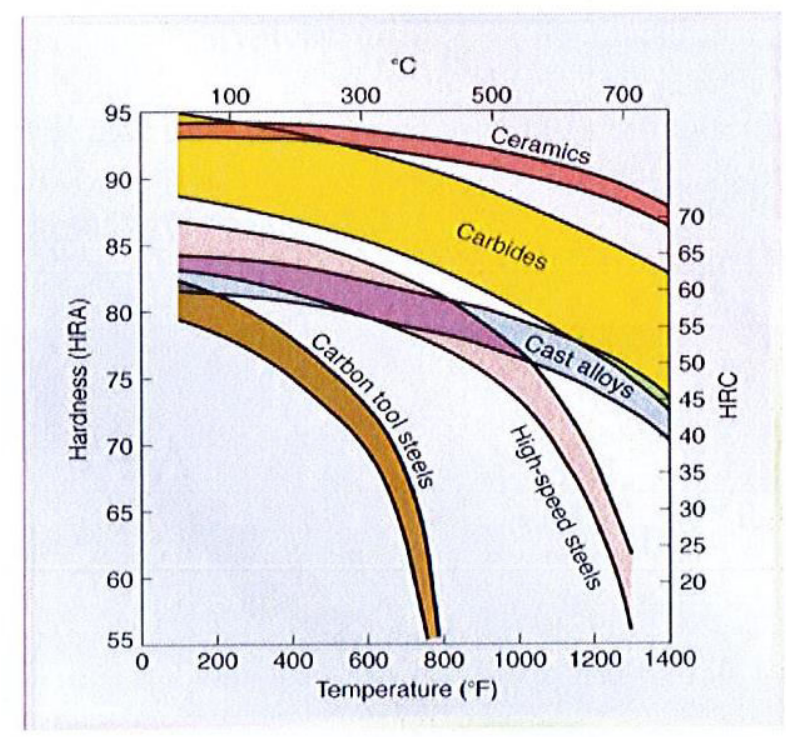

Figure 1. Hot hardness of cutting tool according to the materials [1]

It is vital so that the hardness, strentgh and wear resistance of the tool are maintained at any temperature encountered in the process. This property ensure that the tool stays in its shape and sharpness without undergoing plastic deformation [2-3]. Since there are so many materials used in machining, the tool life varies from the material used. As the time of cutting increase. The tool wear increase as shown on Figure 2 [4].
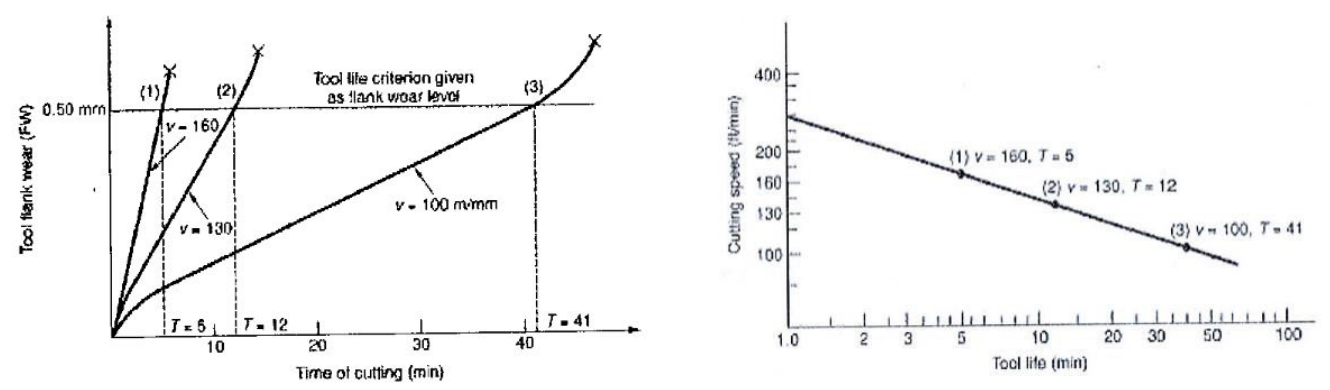

Figure 2. Relationship between time of cutting and cutting speed with tool life [4]

Typically, there are two methods of detecting tool wear, indirect and direct method. As one of the widely used, due to low price, easy to work on and online continuous testing characteristic vibration measurement, is the indirect sensor based method. Many of experiments has been carried out to correlate tool wear and the vibration signal produced. The results does show the tool wear are sensitive to the vibration signature features extracted from the time and frequency domain [5-7].

In prevoius study, the main purpose of vibration analysis is to identify the features indicative of tool wear. In the experiment done by Baojia Chan, a total of 12 cutting tools vibration signal and wear data were measured [8] and it is that all investigated tools have the same wear mechanism and vibration characteristics with increasing tool wear. This study shown, the on-line vibration signals at the sampling frequency $32.768 \mathrm{~Hz}$, is the frequency characteristics of tool vibration. After running 78 mins, the vibration spectrum of the tool divided by two frequency ranges of $2-4 \mathrm{kHz}$ and $7-10 \mathrm{kHz}$ as shown in Figure 3 [8]. 

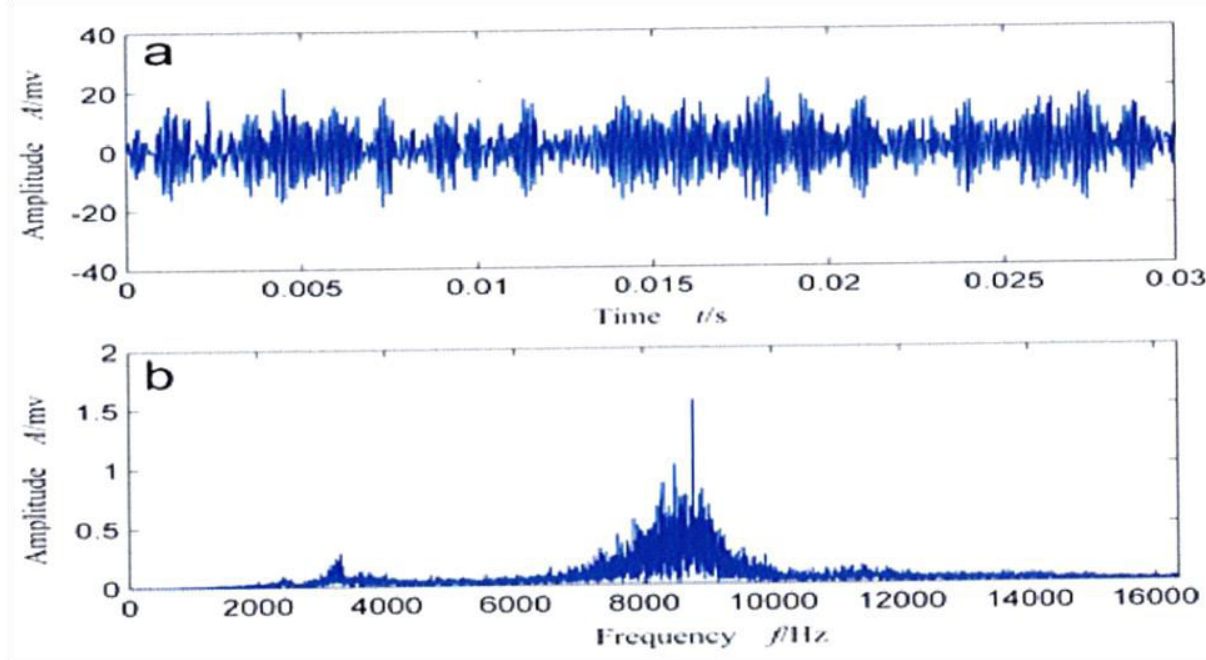

Figure 3. Vibration signal in time domian and frequency domian [8]

\section{Methodology}

The turning experiment is conducted by using Aluminum Alloy 6061 as the specimen. During the turning process the specimen rotating in high revolution and this will generated the vibration signal even before cutting tool contact the specimen. The main purpose of this process is to identify the vibration level of the turning lathe machine. The vibration signal of the turning lathe machine in free of contact will be record, and it is following by contact between cutting tool and specimen, and during cutting process with different depth and speed.

The setup of the equipment, the speed of spindle rotation, location of the transducer, and the cutting first point should considered thoroughly as these are the important factors that will influence the result of the experiment. A piezoelectric accelerometer was attach on the cutting tool holder to measure the vibration during cutting process and convert the signal into another form readable by the data acquisition system (DAQ). For each depth, the vibration of the cutting tool holder was recorded when it is being cutting. The vibration signals were analyzed using MATLAB in time domain to obtain the required parameter such as maximum amplitude and vibration energy.

In this study, the specimen is Aluminum Alloy 6061 with ultimate tensile strength $124 \mathrm{MPa}$ and Hardness 30 . The measurement of the cutting tool vibration will be done at cutting speed $72 \mathrm{rpm}$ and $1750 \mathrm{rpm}$ with depth of cut $2 \mathrm{~mm}$ and $5 \mathrm{~mm}$. The transducer used for this study was Sub miniature Charge Accelerometer, Type 4374 with Bruel\&Kjaer Portable Pulse 3560-C used to analyses the signal converted by accelerometer. The vibration signal was analyzed and visualized by using B\&K Pulse LabShop software. For heat measurement, HotShot thermography camera was used. This thermography camera is incorporates a high performance micro bolometer infrared focal plane array with accurate temperature measurement from $-20^{\circ} \mathrm{C}$ to $250^{\circ} \mathrm{C}$.

\section{Result and Discussion}

Results of this study will be started with vibration wave propagation for rotation speed in $72 \mathrm{rpm}$ and 1750 rpm in different condition. Figure 4 shown time domain vibration wave at rotation without cutting, Figure 5 shown time domain vibration wave during point of cutting, Figure 6 shown time domain vibration wave during cutting process $2 \mathrm{~mm}$ depth of cut, Figure 7 shown time domain vibration wave during cutting process $5 \mathrm{~mm}$ depth of cut, and Figure 8 shown time domain vibration wave during $1750 \mathrm{rpm}, 5 \mathrm{~mm}$ depth of cut with worm cutting tool. 

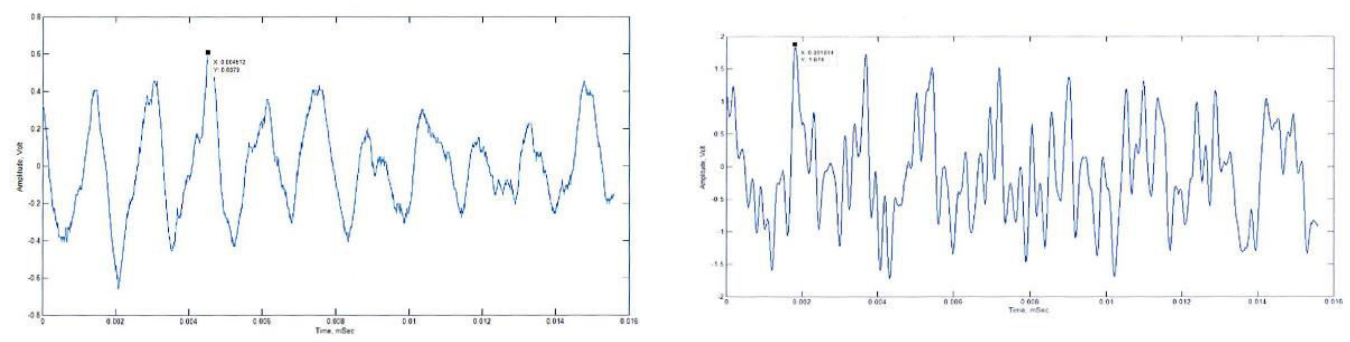

Figure 4. Time domain vibration wave at rotation speed 72 and $1750 \mathrm{rpm}$ without cutting process
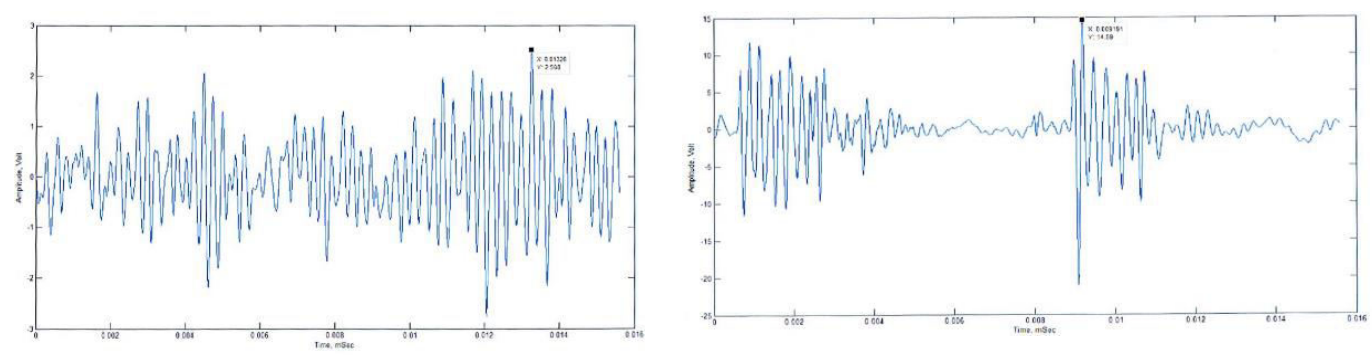

Figure 5. Time domain vibration wave at rotation speed 72 and $1750 \mathrm{rpm}$ during position point of cutting
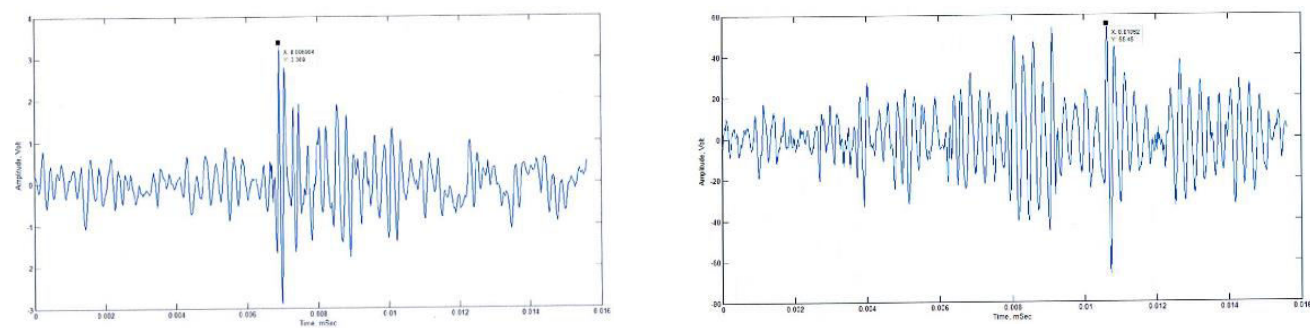

Figure 6. Time domain vibration wave at rotation speed 72 and $1750 \mathrm{rpm}$ during $2 \mathrm{~mm}$ depth of cut
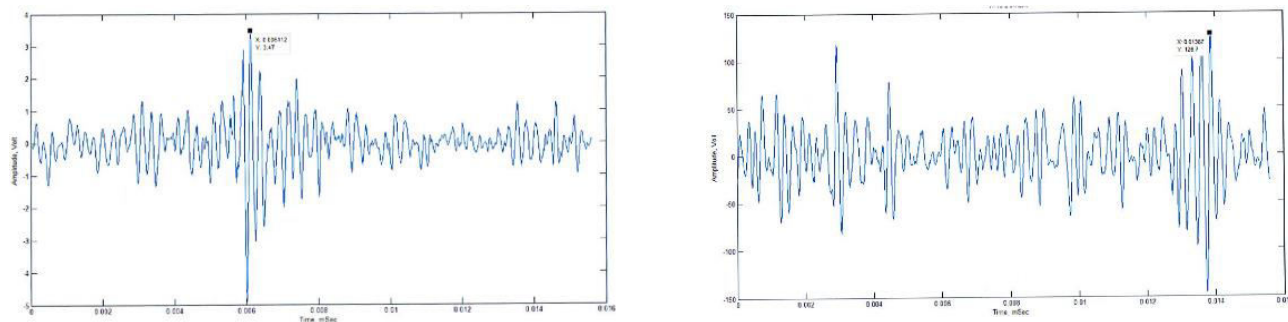

Figure 7. Time domain vibration wave at rotation speed 72 and $1750 \mathrm{rpm}$ during $5 \mathrm{~mm}$ depth of cut

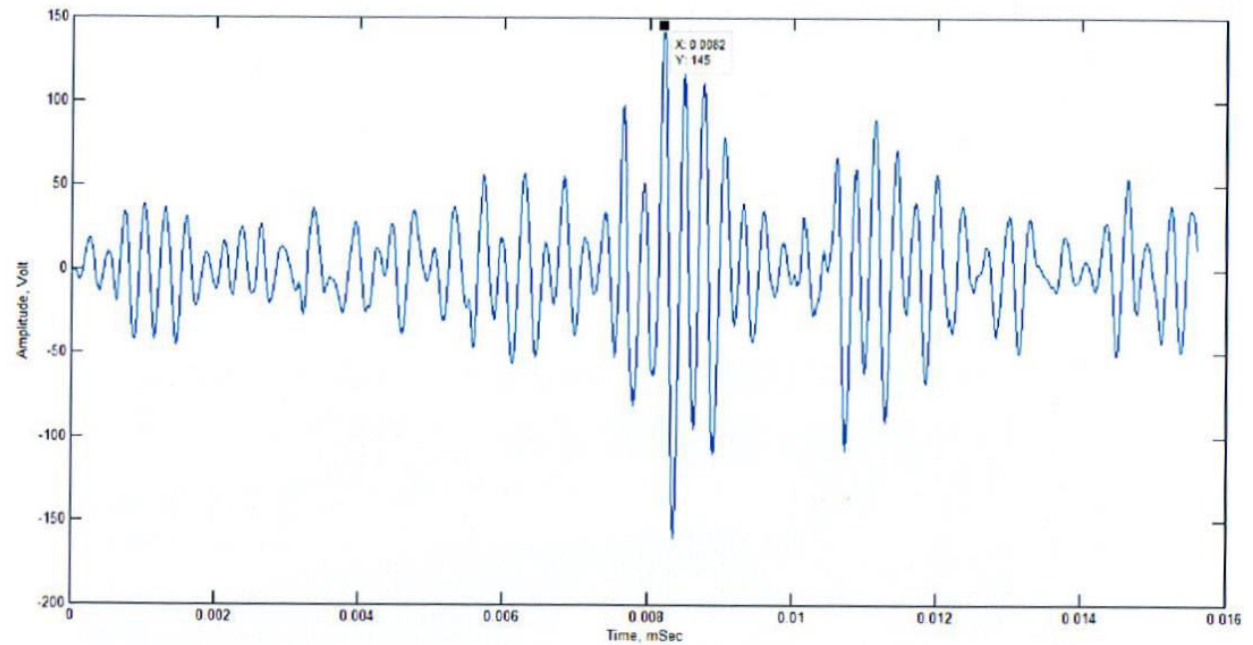

Figure 8. Time domain vibration wave at rotation speed $1750 \mathrm{rpm}, 5 \mathrm{~mm}$ depth of cut with worm cutting tool 
In thermal analysis, Figure 9 shown the thermal image of rotation speed 72 and $1750 \mathrm{rpm}$ during $2 \mathrm{~mm}$ depth of cut. Figure 10 shown the thermal image of rotation speed 72 and $1750 \mathrm{rpm}$ during $5 \mathrm{~mm}$ depth of cut, and Figure 11 shown the thermal image of rotation speed $1750 \mathrm{rpm}, 5 \mathrm{~mm}$ depth of cut with worm cutting tool.
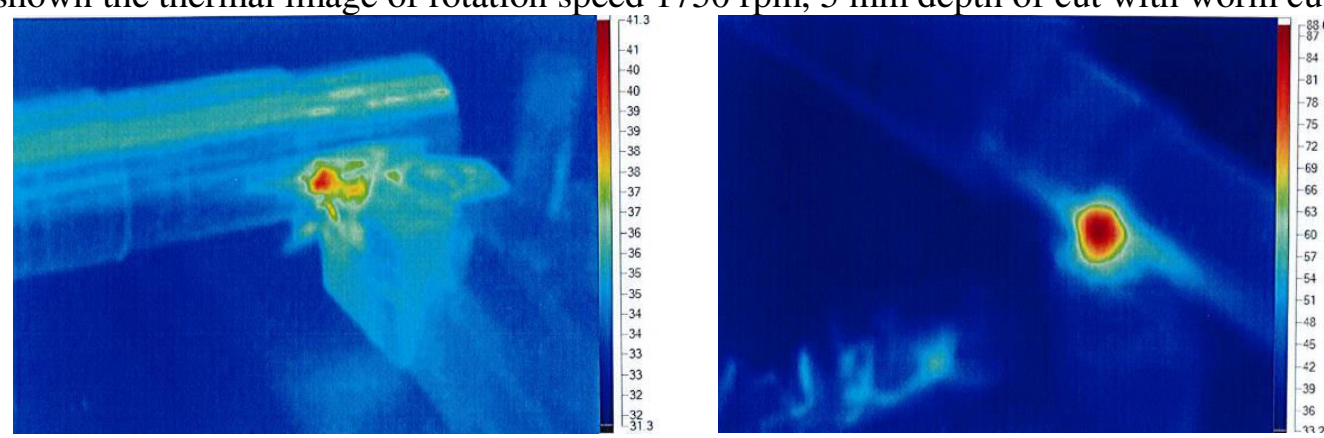

Figure 9. Thermal image during 72 and $1750 \mathrm{rpm}, 2 \mathrm{~mm}$ depth of cut
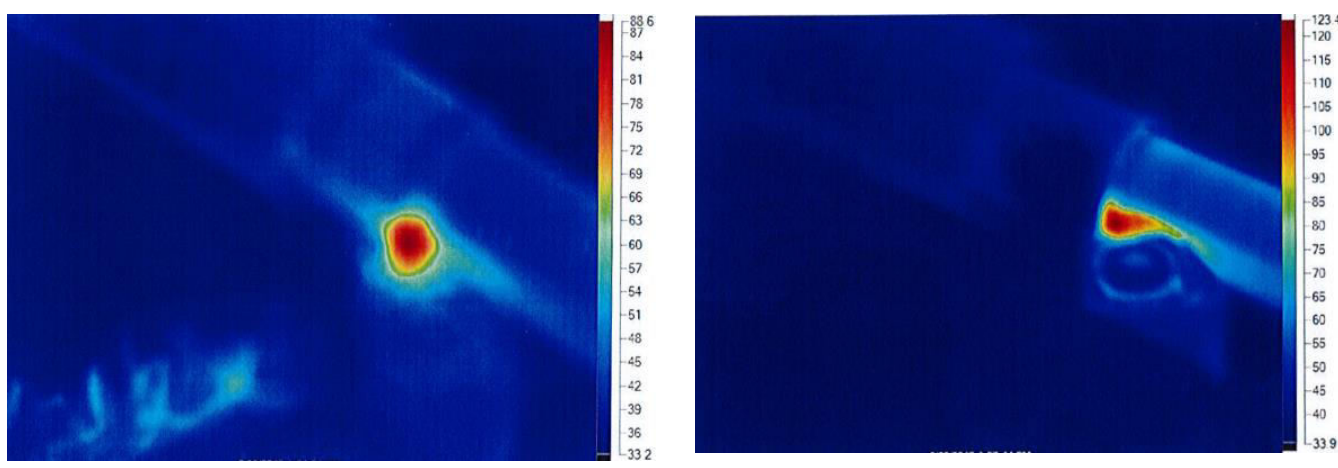

Figure 10. Thermal image during 72 and $1750 \mathrm{rpm}, 5 \mathrm{~mm}$ depth of cut

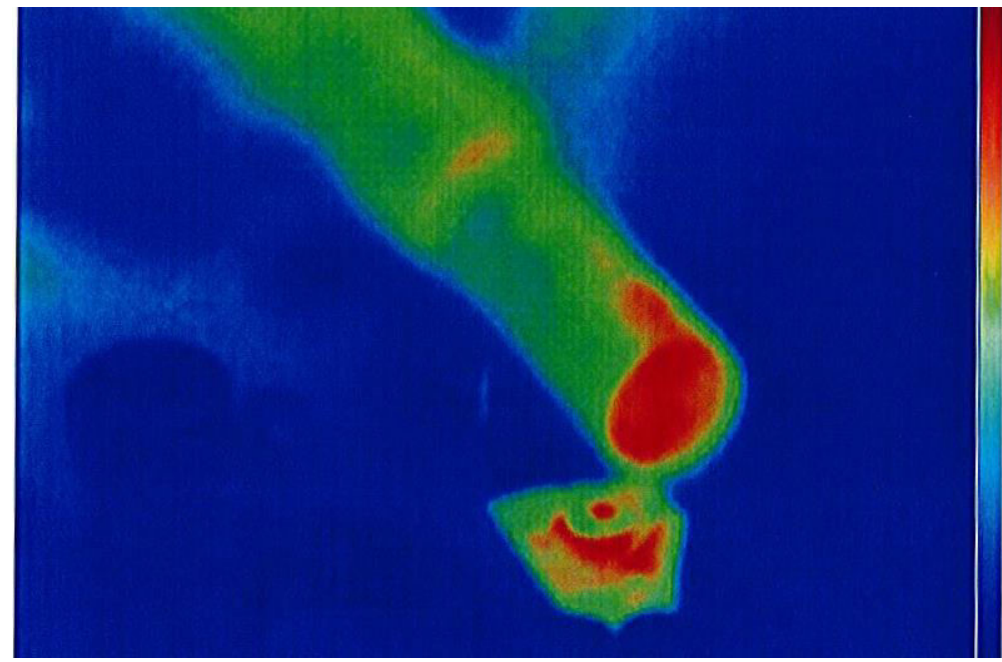

Figure 11. Thermal image of worm cutting tool during $1750 \mathrm{rpm}$ and $5 \mathrm{~mm}$ depth of cut

The value of maximum amplitude, vibration energy, and temperature for lathe machine, when the cutting tool touched the surface of the aluminum, when cutting processes of 2 and $5 \mathrm{~mm}$ depth of cut, and when worm cutting tool is tabulated in Table 1.

Table 1 shown the vibration energy increase with the depth of cut for $72 \mathrm{rpm}$ and $1750 \mathrm{rpm}$ spindle rotation speed. Due to increasing of depth of cut, force imposed by cutting tool on specimen experience increase. This will be the main cause the increasing of pressure towards specimen. The resistance of the point of contact between cutting tool and specimen increased and it is produced more vibration activities. The cause of wear is due to the abrasion and adhesion which occurs when cutting tool and specimen are enforced in cutting process. 
Table 1. Maximum amplitude, vibration energy and temperature for each processes

\begin{tabular}{clccc}
\hline $\begin{array}{c}\text { Speed } \\
(\mathrm{rpm})\end{array}$ & \multicolumn{1}{c}{ Position } & $\begin{array}{c}\text { Maximum } \\
\text { Amplitude } \\
\text { (Volt) }\end{array}$ & $\begin{array}{c}\text { Vibration } \\
\text { Energy } \\
(\text { Joule })\end{array}$ & $\begin{array}{c}\text { Temperature } \\
\left({ }^{\circ} \mathrm{C}\right)\end{array}$ \\
\hline 72 & Without cut & 0.6079 & 205.2137 & - \\
& Cutting point & 2.5077 & 291.6156 & - \\
& Depth cut 2 mm & 3.3689 & 423.3078 & 41.30 \\
& Depth cut 5 mm & 3.4703 & 477.0082 & 88.60 \\
\hline 1750 & Without cut & 1.8744 & 616.1857 & - \\
& Cutting point & 14.590 & 2108.400 & - \\
& Depth cut 2 mm & 55.448 & 12324.00 & 104.3 \\
& Depth cut 5 mm & 126.70 & 23871.00 & 123.4 \\
& Depth cut 5 mm (worm) & 147.25 & 25680.00 & 167.1 \\
\hline
\end{tabular}

Increasing the degree of wear of cutting tool, led to an increase in the control area owing to crumbled of cutting edges. The transition of friction from static to sliding owing increasing of the contact area which generated the strong vibration waves [9]. This will be form instabilities before the structure started develop the crack point at the cutting tool especially in contact area. These instabilities results also form existence of plastic deformation and propagation of crack.

In high speed of cutting of cutting it is noticeable, the rate of increment of vibration energy via increment depth of cut is higher compared to vibration energy produced in lower speed turning. This shown the vibration energy is significant increment as the spindle speed increase. During free run or turning with cutting process, shown the vibration produced at low speed is relatively small due to damper of the rotating motor. In other way, increasing the spindle speed will be increase the lathe machine vibration internally. This discovery useful to re-location test and identified the suitable vibration damper pad to reduce the machine vibration in high speed operation.

When the cutting tool touches the turning specimen it creates vibrations due to the roughness of the specimen. Once cutting tool touches that point, the oxide layer of specimen establish the friction and produced the vibration wave. This scenario will be happen for all speed of spindle and vibration energy increased in trend of exponential. This trend almost same for cutting process with the different depth of cut. In other part, increasing of vibration energy it is directly proportional to temperature of heat release. It is clearly shown between good cutting tool and worm cutting tool.

\section{Conclusion}

In this study, the experiment was mainly to study the mechanical behavior of the cutting tool during turning, the relationship of cutting speed and depth of cut to the tool wear by analyzing vibration wave and for early detection of tool wear. However, the differences values and trend of maximum amplitude and vibration energy does give us an overview of the effect of the cutting speed and the depth of cut which related to the tool wear. There are two important similarities can be observed by this experiment. The minimum tool wear occurs at the optimum cutting speed and optimum depth of cut since the vibration energy is directly proportional to the tool wear.

\section{References(11 PT)}

[1]. S. Kalpakjian, and S. Schmid, Manufacturing Process for Engineering Materials, New Jersey, USA: Pearson Education, 2017, 6th Editions.

[2]. R. F. Brito, S. R. Carvalho, S. M. M. L. Silva, and J. R. Ferreira, "Thermal Analysis in Coated Cutting Tools," Int. Communications in Heat and Mass Transfer, vol. 36 (4), pp. 314-321, April 2009

[3]. Y. Cerci, P. Pemiroioglu, I. Bogrekei, C. Denis, and N. M. Durakbasa, "Case Study in Thermal and Wear Analysis for Cutting Tool," in Proc. 11th Int. Symposium on Measurement and Quality Control, 2013

[4]. M. P. Groover, Principles of Modern Manufacturing, USA: John Wiley and Sons, 2013, 5th Editions.

[5]. W. Rmili, R. Serra, A. Ouahabi, C. Gontier, and M. Kisio, "Tool Wear Monitoring in Turning Process Using Vibration Measurement," in Proc. 13th Int. Congress on Sound and Vibration, 2008. 
[6]. S. Orhen, A. Osman, N. Camuscu, and E. Aslan, "Tool Wear Evaluation by Vibration Analysis during End Milling of AISI D3 Cold Work Tool Steel with 35 HRC Hardness," NDT\&E Int., vol. 40 (2), pp 121-126, 2007.

[7]. M. S. H. Bhuriyan, and I. A. Choudhury, "Investigation of Tool Wear and Surface Finish by Analyzing Vibration Signals in Turning Assab-705 Steel," Marching Sensor and Technology, vol. 19 (2), pp 236-251, 2015.

[8]. B. Chen, "Reliability estimate for cutting tools based on logistic regression model using vibration signals," Journal of Mechanical Systems and Signal Processing, vol. 25 (7), pp 2526-2537, 2011.

[9]. D. E. Dimla, "The Correlation of Vibration Signal Features to Cutting Tool Wear in a Metal Turning Operation," The Int. Journal of Advanced Manufacturing Technology, vol. 19 (10), pp 705-713, 2002. 